\title{
Excellent Thinking and its Position among EFL Learners
}

\author{
Gholamhossein Shahini*, Zahra Nouri
}

Department of Foreign Languages and Linguistics, Shiraz University, Iran

Corresponding Author: Gholamhossein Shahini, E-mail: ghshahini@rose.shirazu.ac.ir

\begin{tabular}{l} 
ARTICLE INFO \\
\hline Article history \\
Received: November 26, 2017 \\
Accepted: January 19, 2018 \\
Published: March 01, 2018 \\
Volume: 7 Issue: 2 \\
Advance access: February 2018 \\
Conflicts of interest: None \\
Funding: None
\end{tabular}

\begin{abstract}
The major goal of education, according to the educationalist Matthew Lipman (2003), is to culture students to become thoughtful by attaining excellent thinking power; i.e. critical, creative, and caring thinking ability. The purpose of this study was to examine the current status of excellent thinking among EFL students. Using accessible sampling, 41 EFL students at Shiraz University, Iran read two passages of various types and were asked to make a number of essay-type questions on each one. The results indicated that the majority of the questions were trivial reading comprehension ones with no sign of excellent thinking. The findings may imply that despite the significance of cultivating excellent thinking within students, no/scant attention is paid to this issue and EFL students have not still gained the necessary skills of excellent thinking.
\end{abstract}

Key words: Excellent Thinking, Critical Thinking, EFL

\section{INTRODUCTION}

Education should develop capabilities within students to be able to think and plunge deeply into subject matters they read and reflect on their surrounding phenomena. This issue is further highlighted by Cam (2006) who argues that students who have not learned to think effectively are comparable to illiterate ones. Cottrell (2005) holds that students need to acquire thinking skills so as to be able to dig beneath the surface and critically evaluate what they read and hear.

The educationalist Matthew Lipman (2003), however, believes that while critical thinking is important and highly valuable, it is not sufficient. Education, according to him, must shape 'creative and caring thinking' within students as well. He adds that the type of thinking, that meets the three dimensions of critical, creative and caring thinking is significantly improved and can be called excellent thinking which is represented in the following Figure 1.

\section{Excellent Thinking Skills}

\section{Critical thinking: what it can be}

To have a clear conception of what critical thinking is, we need to know its defining features, its characteristic outcomes, and the underlying conditions that make it possible. Scholars in this field have provided different definitions of the term critical thinking. However, Lipman (2003) holds that they often stress outcomes of such thinking and fail to mention its essential characteristics. For example, Sternberg (1985, p. 46) defines critical thinking as "the mental processes, strategies and representations people use to solve problems, make decisions and learn new concepts." Or Ennis (1987) co ceives critical thinking as "reasonable reflective thinking that is f cused on what to believe or do" (p. 10). These definitions, according to Lipman (2003), provide insufficient enlighte ment since the outcomes (solutions, decisions, and acquisition of concepts) are too narrow, and the defining characteristics (reasonable, reflective) are too vague. Therefore, he broadens the definition in a way that critical thinking "1) facilitates judgment because it 2) relies on criteria 3) is self-correcting, and 4) is sensitive to context" (p. 212).

Considering the above-mentioned points, it is important to add something about the logical operations of critical thinking which can be the manifestation of a critical mind. Gregory (2008, p. 37) lists the basic operations of critical thinking as follows:

- Agreeing or disagreeing

- Criticizing

- Giving reason

- Giving example or counterexample

- Classifying/Categorizing

- Making a comparison

- Making a distinction

- Making a connection

- Making an analogy

- Offering a definition

- Identifying assumption

- Making inference

- Making conditional statement

- Reasoning syllogistically

- Restating

- $\quad$ Entertaining different perspectives. 


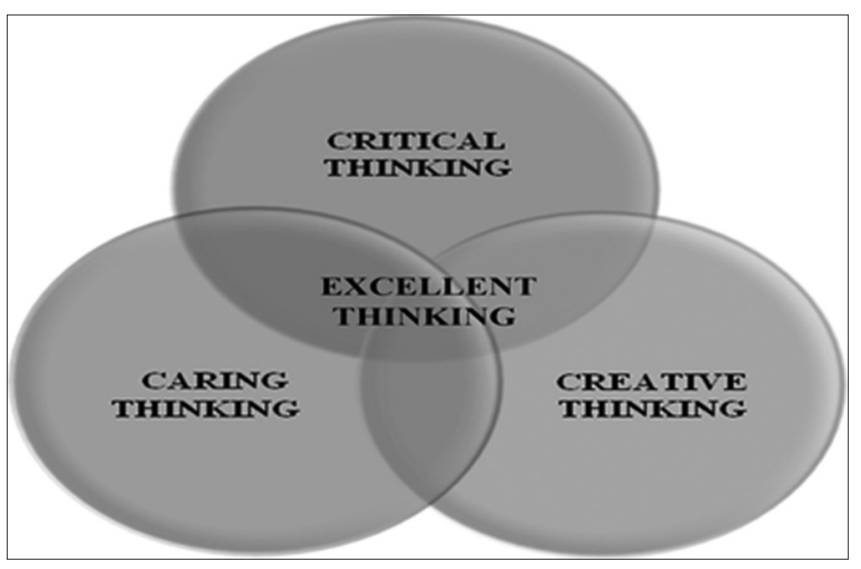

Figure 1. Three dimensions of excellent thinking

(Extracted from Lipman, 2003, p. 200)

\section{Creative thinking and its characterizations}

According to Adair (2007), creative thinking, in general, holds the principles of creativity. Like a masterpiece by an artist which was once a collection of blue, red, yellow, and green worms of paint on his palette, in creative thinking "perception, ideas and feelings are combined in a concept or vision" (p. 6). He then explains that the creative mind can see possibilities in the surrounding world that is invisible to less creative minds. The point, however, is that in order to be seen as a creative thinker, the result needs to be a valuable combination of ideas or things that were not thought to be linked so far.

Lau (2011) holds that since creativity is not just coming up with something new and is a matter of generating new ideas that are useful, critical thinking should come to help. First, we use critical thinking, he says, to analyze a problem as well as to understand the limitations of existing solutions. So, we can realize what a better solution looks like. Then, when having a new solution, critical thinking can help us to determine whether it really works or not. This is in line with Lipman's (2003) view who maintains that creative thinking will be at least somewhat critical. That is, creative thinking has both critical and creative characterizations. Some of these characterizations, as he describes, are:

- Originality. Thinking for which no clear precedents are available. Originality alone is not sufficient, since some products might be highly original but eccentric or irrational. This is why a number of criteria need to be used.

- Productivity. Thinking that is when applied in problematic situations, brings successful results. This is a value-concept that heavily relies on consequentialist considerations.

- Imagination. Creative thinkers can envisage a possible world, or the details of such a world. They should have other worlds in which to dwell and make them available to others to dwell in, as well. What matters here is that in exploring possibilities, they must retain their sense of fact as much as possible.

- Holism. In creative thinking, the emerging character of the whole plays an important role in determining the progressive selection of additional parts. Therefore, the finished product always shows the part-whole and means-ends relationships that give the product its idiosyncratic meanings.

- Expression. Creative thinking both expresses the thinker as well as what is thought about. For example, to think creatively about a tree indicates the character of the tree and that of the thinker.

- Inventiveness. A great number of solutions to a problem can be considered as inventive, but to be creative it needs to meet other criteria. Although inventiveness can be regarded as a necessary condition for creativity, it is not sufficient (pp. 245-247).

\section{Caring thinking: the place of passions in thinking}

Lipman (2003) holds that our emotions profoundly shape and direct our thoughts, provide them with a framework, with a sense of proportion, and with a number of different perspectives. Thinking without emotions, he says, would be flat and uninteresting. He sees caring thinking as having five distinct, but interrelated, aspects:

1. Valuational (appreciative) thinking

Since to value is to appreciate, to prize, to cherish, or to hold dear, valuational thinking implies to highly appreciate or prize (Lipman, 2003).

2. Affective thinking

Affective thinking, as Brunt (2003) elaborates, is the emotional response to a wrong doing by a person having a clear understanding of right and wrong, and a strong sense of justice. They feel empathy and respond to the injustice that has been done to an innocent person or creature.

3. Active thinking

As Brunt (2003) explains, active thinking is about using language, gesture, planning and/or action to support a cause or belief. It is actually focusing on what I can do about a circumstance rather than being overwhelmed and feeling helpless.

4. Normative thinking

Normative thinking, as Brunt (2003) points out is about understanding the reality of the situation but having a sense of idealism of things could, or should, be.

5. Empathic thinking

The term empathy, according to Lipman (2003), has to do with what happens when we put ourselves into another's situation and experience that person's emotions as if they were own. Hence, empathic thinking is to step out of your own feelings and imagine ourselves as having the feeling of another.

\section{Different Types of Questions}

\section{Routine questions}

As Scholl (2010) explains, routine questions are ones for which settled answer/s exist. The answer may need a little research, but certainly there will be a correct answer, or in some cases more than one correct answer. They then leave no room for discussion. 
Routine questions can be categorized into reading comprehension questions and factual questions. Reading comprehension questions as the name suggests, are related to the text read. Raising such questions only indicates that students have comprehended the text. Factual knowledge questions, on the other hand, solicit reasonably simple, straight- forward answers based on obvious facts. They may be easily responded by asking a friend or the teacher, by a trip to the library, or by a web search (Cam, 2006). Consider the following examples:

- How many miles can a car travel on a tank of gas?

- What time is it?

- Who was the first US president?

- What year did the Titanic sink?

- How many languages do people speak in India?

- What did you have for breakfast this morning?

\section{Critical, creative, and caring questions}

Based on the aforementioned characteristics of critical, creative, and caring thinking, the questions of these types can be outlined as follows:

- Critical questions mainly look for criticizing and offering reasons. Hence, they usually begin with 'Why' or 'How'. For example:

- Could you explain why this is so?

- What are the reasons for .......?

- How could you defend the .......?

- Why was ......... better than .......?

- Creative questions primarily have their eye on speculation, imagery, creation, and elaboration. For instance:

- What would you do if you had a trunk?

- What does this color make you think of?

- Do dinosaurs have friends?

- What would happen if you could fly?

- What do you think would be most exciting about living underwater?

- How do you think tomorrow gets here, to where we are?

- What would that noise look like if we tried to draw it?

- $\quad$ Caring questions are concerned with emotive thinking. Questions like:

- How should I sympathize with someone?

- How can someone control his feelings in a dangerous situation?

- How can I help to solve someone's problem?

- How should we respond to the injustice been done to an innocent person?

\section{Objective of the Study}

Given the significant role thinking skills can occupy in today's fast-changing world, the present study intended to investigate the status of excellent thinking among Iranian EFL learners. Hence, the following research question can be proposed:

- What is the status of excellent thinking among Iranian EFL learners?

\section{LITERATURE REVIEW}

Various pieces of research have been carried out on exploring the status of critical thinking among Iranian students of which four are presented below:

Aziz-Fini, Hajibagher, and Adib-Hajbaghery (2015) examined the critical thinking skills of freshmen and senior nursing students. 150 undergaduate freshmen and senior nursing students in Kashan University of Medical sciences attended the study using the census method. A questionnaire including questions on demographic data and the California Critical Thinking Skills Test, form B were utilized to gather the data. The results revealed that both groups possessed low level of critical thinking skills.

Amir Khandaghi, Pakmehr, and Amiri (2011) measured students' critical thinking dispositions in humanities fields. Using stratified sampling, 123 students were randomly chosen among students in the College of $\mathrm{Hu}-$ manities in Ferdowsi University of Mashhad, Iran. Ricketts'(2003) Critical Thinking Disposition Questionnaire was utilized. The results indicated that all the participants attained optimal level of critical thinking in the moderated level.

Eslami and Maarefi (2010) investigated critical thinking abilities among the first and last term baccalaureate nursing students and clinical nurses of Jahrom University of Medical Sciences. The study was a cross-sectional one and the data was collected through Watson and Glaser standard questionnaire (form A). The validity and reliability of the instrument was checked in a pilot study. The participants of the study were 53 first term and last term baccalaureate nursing students and 41 baccalaureate clinical nurses. The results showed weak critical thinking abilities in the study groups.

Anajafi, Zeraat, Soltan Mohammadi, Ghabchipour, and Kohan (2009) evaluated the critical thinking skills in engineering and human sciences students of Shiraz University. The study was done on 200 students selected through randomized sampling. The form of California critical thinking skills was the instrument of data collection. The findings disclosed the low level of critical thinking skills in both groups.

Cam (2006) argues that "if only people were better at asking appropriate questions, articulating problems and issues, imagining life's possibilities, seeing where things lead, and evaluating the alternatives open to them, then we would all be so much better off" (p. 2). He then adds that a widescale enhancement in such abilities may be no cure to all the issues we face in life, but surely it would be one of the most significant educational accomplishments that we could expect to address the problems of life and society. In fact, as Cam states, "no developed society would tolerate unchecked endemic disease in the way that we suffer from the consequences of widespread poor thinking in our society" (p. 2) With regard to the comprehensiveness of excellent thinking and the crucial role it plays in education, no qualitative research, to gain an in-depth understanding of its status, has ever been done. 


\section{METHOD}

\section{Design}

This study adopted a qualitative approach in which content analysis was used to show the status of excellent thinking reflected through questions raised by the participants.

\section{Participants}

To select the participants, accessible sampling was used. A group of 41 BA EFL students (21 female and 20 male) at Shiraz University, Iran attended the study. The participants ranged in age from 20 to 33 .

\section{Instruments}

Two short simple passages of different types, one story and the other non-story, were utilized to elicit and evaluate the participants' excellent thinking ability. Two texts were used so that the participants would get the chance to make more questions. Moreover, the passages were of different types not to limit the participants to make questions based on a specific genre.

As the purpose of the study was not to examine the participants' reading comprehension, simple texts were chosen and some minor modifications including word simplification and deletion were applied to make the texts for the participants easy to follow and simple to understand.

\section{Data Collection Procedure}

To collect the data, all the participants were asked to read the two texts one by one and write whatever question (open- ended) came to their mind concerning each one. It should be mentioned that the participants, while being served, were highly and repeatedly reminded to formulate whatever questions came to their mind on each text. The data collection approximately lasted for two hours.

\section{Data Analysis Procedure}

To analyze the collected data, the number of questions was obtained through frequencies. The types of questions were qualitatively identified through content analysis. Finally, the results of the study were descriptively reported.

\section{RESULTS AND DISCUSSION}

Scrutinizing the questions, they were categorized as routine (reading comprehension) and critical, creative, and caring questions. The number and type of questions raised by the participants are represented in the following Table 1.

As it is illustrated, the number of the questions posed by the participants is not distributed equally since the majority of the questions belong to routine questions while the minority pertains to critical, creative, and caring questions.

By taking a close look at the table, one can see that routine questions have gained the highest number of questions
Table 1. Analysis of the questions made by Shiraz University BA EFL students

\begin{tabular}{|c|c|c|c|}
\hline Participants & $\begin{array}{l}\text { No. of } \\
\text { routine Qs. }\end{array}$ & $\begin{array}{l}\text { No. of critical, } \\
\text { creative, caring Qs. }\end{array}$ & Total \\
\hline Participant1 & 38 & 6 & 44 \\
\hline Participant2 & 28 & 8 & 36 \\
\hline Participant3 & 35 & 0 & 35 \\
\hline Participant4 & 34 & 4 & 38 \\
\hline Participant5 & 30 & 5 & 35 \\
\hline Participant6 & 39 & 0 & 39 \\
\hline Participant7 & 35 & 0 & 35 \\
\hline Participant8 & 36 & 8 & 44 \\
\hline Participant9 & 26 & 0 & 26 \\
\hline Participant10 & 38 & 7 & 45 \\
\hline Participant11 & 17 & 0 & 17 \\
\hline Participant 12 & 23 & 0 & 23 \\
\hline Participant13 & 29 & 9 & 38 \\
\hline Participant14 & 23 & 0 & 23 \\
\hline Participant15 & 20 & 10 & 30 \\
\hline Participant16 & 39 & 0 & 39 \\
\hline Participant17 & 37 & 11 & 48 \\
\hline Participant18 & 32 & 0 & 32 \\
\hline Participant19 & 21 & 6 & 27 \\
\hline Participant20 & 33 & 7 & 40 \\
\hline Participant21 & 25 & 0 & 25 \\
\hline Participant22 & 18 & 7 & 25 \\
\hline Participant23 & 37 & 0 & 37 \\
\hline Participant24 & 38 & 9 & 47 \\
\hline Participant25 & 25 & 5 & 30 \\
\hline Participant 26 & 32 & 2 & 34 \\
\hline Participant27 & 26 & 11 & 37 \\
\hline Participant28 & 37 & 0 & 37 \\
\hline Participant29 & 16 & 7 & 23 \\
\hline Participant30 & 40 & 7 & 47 \\
\hline Participant 31 & 33 & 0 & 33 \\
\hline Participant32 & 25 & 5 & 30 \\
\hline Participant33 & 39 & 7 & 46 \\
\hline Participant34 & 37 & 8 & 45 \\
\hline Participant35 & 32 & 6 & 38 \\
\hline Participant36 & 24 & 4 & 28 \\
\hline Participant37 & 14 & 14 & 28 \\
\hline Participant38 & 20 & 12 & 32 \\
\hline Participant39 & 17 & 9 & 26 \\
\hline Participant 40 & 22 & 5 & 27 \\
\hline Participant41 & 27 & 6 & 33 \\
\hline Total & 1195 & 208 & 1403 \\
\hline
\end{tabular}

(1195 out of 1403) and in some cases all the questions made by a participant only belong to this type. In contrast, critical, creative, and caring questions have received only 208 ques- 


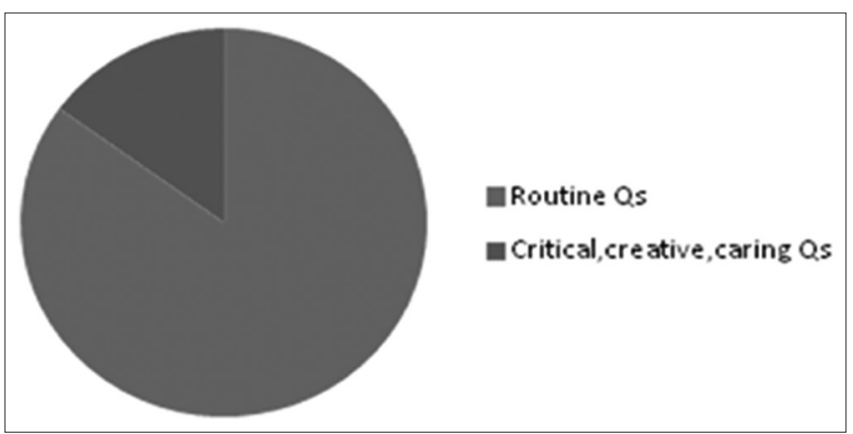

Figure 2. Comparison between routine questions and critical, creative, and caring questions in terms of number and type

tions out of 1403. The following graph depicts the above numerical data more clearly (Figure 2).

Concerning the routine questions, it should be mentioned that they are reading comprehension ones which are trivial, text-bound, and have only one single true answer. In other words, they possess no sign of excellent thinking and indicate that the students have not been able to see beyond the texts. Ghanbari (2011) also in his study revealed that few signs of critical thinking were observed in the questions posed by the Iranian TEFL students in classrooms and their questions mostly revolved around comprehension and knowledge.

Students' bias towards sticking to the text and not posing thoughtful questions could shed light upon the fact that what we are witnessing, as Lipman (2003) points out as well, is schooling without thinking. Students find the school an unchallenging environment that gradually makes them become passive, and lose their curiosity and inquisitiveness. The system of learning is mainly memorization-based and not thought-provoking. Too much emphasis of educational system on memorization has led to posing questions and having discussions at factual and information-based level (Risner, Skeel, \& Nicholson, 1992; Orlich, Harder, Callahan, Trevisan, \& Brown, 2010).

Critical, creative, and caring questions posed by the participants cannot be responded based on the texts. That is, they are detached from the texts. This may imply that the texts have made the students think. In fact, they have aroused the students' curiosity and their answers cannot be settled by reference to the texts, established facts, or even one's learning. Students' tendency to delve into the text and raise deeper questions could be traced in their willingness not to restrict themselves to stop at the surface. In fact, such a person, as Cottrell (2005) states, "is disposed to delve below the surface with the aim of developing deeper insights and awareness" (p. 227).

\section{CONCLUSION}

Based on the findings, it can be concluded that the participants under investigation are accustomed to reading the lines, not between the lines. Moreover, critical, creative, and caring questions with low frequencies (208 out of 1403) may indicate that Iranian EFL students are not empowered with excellent thinking. It may imply that despite the significance of cultivating excellent thinking within students, no/scant attention is paid to this issue and in the educational system of Iran factual knowledge is more valued.

\section{IMPLICATIONS OF THE STUDY}

The implications of the present study may a) make all stakeholders become aware of the need to bring excellent thinking to classrooms, b) reduce imitation and memorization and help students become thoughtful and reflective in their thinking process, and c) pave the way for critical, creative, and caring questions to be included in texts and reading passages.

\section{REFERENCES}

Adair, J. (2007). The art of creative thinking: How to be innovative and develop great ideas. London and Philadelphia: Kogan Page Limited.

Amin Khandaghi, M., Pakmehr, H., Amiri, E. (2011). The status of college students' critical thinking disposition in humanities. Procedia Social and Behavioral Sciences, $15,1866-1869$.

Anajafi, F., Zeraat, Z., Soltan Mohammadi, Z., Ghabchipour, K., \& Kohan, F. (2009). Critical thinking skills of engineering and human sciences students. Journal of Education Strategies, 2(1), 19-22.

Azizi-Fini, I., Hajibagheri, A., Adib-Hajbaghery, M. (2015). Critical thinking skills in nursing students: A comparison between freshmen and senior students. Nursing and Midwifery Studies, 4(1), 1-5.

Brunt, J. (2003). Caring thinking: The new intelligence. Australasian Journal of Gifted Education, 12, 13-25. Cam, P. (2006). 20 thinking tools. Victoria: ACER Press.

Cam, P. (2006). 20 thinking tools. Victoria: ACER Press.

Cottrell, S. (2005). Critical thinking skills: Developing effective analysis and argument. Basingstoke: Palgrave Macmillan.

Ennis, R. H. (1987). A taxonomy of critical thinking dispositions and abilities. New York: Freeman.

Eslami, A., Maarefi, F. (2010). A comparison of the critical thinking ability in the first and last term baccalaureate students of nursing and clinical nurses of Jahrom University of Medical Sciences in 1386. Journal of Jahrom University Medical Sciences, 8(1), 38-45.

Ghanbari, A. (2011). A pathological inquiry into the limits and howness of critical thinking in Shiraz University post- graduate classroom discourse (Unpublished M.A. thesis). Shiraz University, Iran.

Gregory, M. (2008). Philosophy for children: A practitioner handbook. Montclair: Institute for the Advancement of Philosophy for Children.

Lau, J. Y. F. (2011). An introduction to critical thinking and creativity. Hoboken, New Jersey: John Wiley \& Sons Inc. Lipman, M. (2003). Thinking in education ( $2^{\text {nd }}$ ed.). 
New York: Cambridge University Press.

Lipman, M. (2003). Thinking in education ( $2^{\text {nd }}$ ed.). New York: Cambridge University Press.

Orlich, D., Harder, R., Callahan, R., Trevisan, M., \& Brown, A. (2010). Teaching strategies: A guide to effective instruction. Boston: Wadsworth Publishing.

Risner, G. P., Skeel, D. J., \& Nicholson, J. I. (1992). A closer look at textbooks: what research says. Science and Children, 30(1), 42-45.

Scholl, R. (2010). The question quadrant: A stimulus for negotiated curriculum. Primary \& Middle Years Educator, 8(2), 3-17.

Sternberg, R. (1985). Critical thinking: Its nature, measurement, and improvement. Alexandria, Va.: ASCD. 